\title{
Drug Sentitivity of Aeromonas liquefaciens Isolated from Freshwater Fishes
}

\author{
Takashi AOKI and Syuzo EGUSA* \\ (Received September 7, 1970)
}

\begin{abstract}
Two hundred and fifty strains of Aeromons liquefaciens isolated from fishes and softshelled turtles were studied for their sensitivity to 9 sorts of chemotherpeutics using agarplate dilution method. One hundred and ten of the 250 strains were additionally tested for sensitivity to 3 other drugs.

Most of the strains tested were highly sensitive to chloramphenicol, chlortetracycline, tetracycline, relatively high sensitive to nifuriprinol, sulfamonomethoxine, and sulfisoxazole and moderately sensitive to fradiomycin, furazolidone, nitrofurazone, streptomycin and kanamycin and resistant to aminobenzyl penicillin.

Criteria for defining resistant strains to the drugs were tentatively determined. According to the criteria out of the 250 strains 28 were one-drug-resistant, 38 were two-drug-resistant, 4 were three-drug-resistant and 8 were four-drug-resistant. Tetracycline-sulfanilamide resistance was a characteristic resistance pattern of drug-resistant $A$. liquefaciens.
\end{abstract}

In recent years a variety of chemotherapeutics have been largely used as feed supplement by fish-culturists in Japan for the prevention or treatment of bacterial diseases. of fishes. It is not seldom that drugs are applied directly to fish ponds. In view of the fact that the use of antibiotics and other chemotherapeutics as feed additives for livestock and poultry has resulted in the increase of drug-resistant enteric bacteria in these animals, ${ }^{11}$ it seems likely that the wide use of chemotherapeutics for fishes has caused the increase of drug-resistant fish-pathogenic bacteria. In fact, we have often heard of reports, though without scientific data, of outbreaks of bacterial fish-diseases that failed to respond to chemotherapy. SNIESzKo and Bullock published two reports on the appearance of drug-resistant Aeromonas salmonicida in 19572,3), but since then no systematic work has been done on this problem either in Japan or abroad.

The present authors have studied the sensitivity of a number of strains of Aeromonas liquefaciens isolated from fishes in fish-farm ponds in various parts of the country, and found that considerable portion of the strains are resistant to any or some of the drugs tested, though the majority were highly or moderately sensitive to most of the drugs. The present paper reports the results of the study.

\section{Materials and Methods}

1) Strains of $A$. liquefaciens studied: Use was made of 250 strains isolated from

* Department of Fisheries, Faculty of Agriculture, University of Tokyo, Tokyo, Japan (青木宙. 江草周三：東京大学拨学部) 
188 eels (Anguilla japonica), 27 carp (Cyprinus carpio), 12 ayu (Plecoglossus altivelis), 21 goldfishes (Carassius auratus), and 2 soft-shelled turtles (Trionyx sinensis japonicus) durging the period from March, 1963 to August, 1969. All the animals from which the strains were isolated were collected from farm-ponds in various parts of Japan, except 6 wild ayu (Table 1). Of the 250 strains, 154 were isolated from diseased individuals and the remaining 96 were from apparently healthy ones.

The identification of A. liquefaciens was based on Bullock's scheme ${ }^{4)}$. According to SCHUBERT's scheme in $1967^{\circ}$, almost all the strains are identified as $A$. hydrophila and a few as $A$. punctata.

2) Chemotherapeutics used: The chemotherapeutics used were tetracycline hydrochloride (Lederle), chloramphenicol (Sankyo), dihydrostreptomycin sulfate (Sankyo),

Table 1. Sources of the 250 strains of Aeromonas liquefaciens used for sensitivity tests.

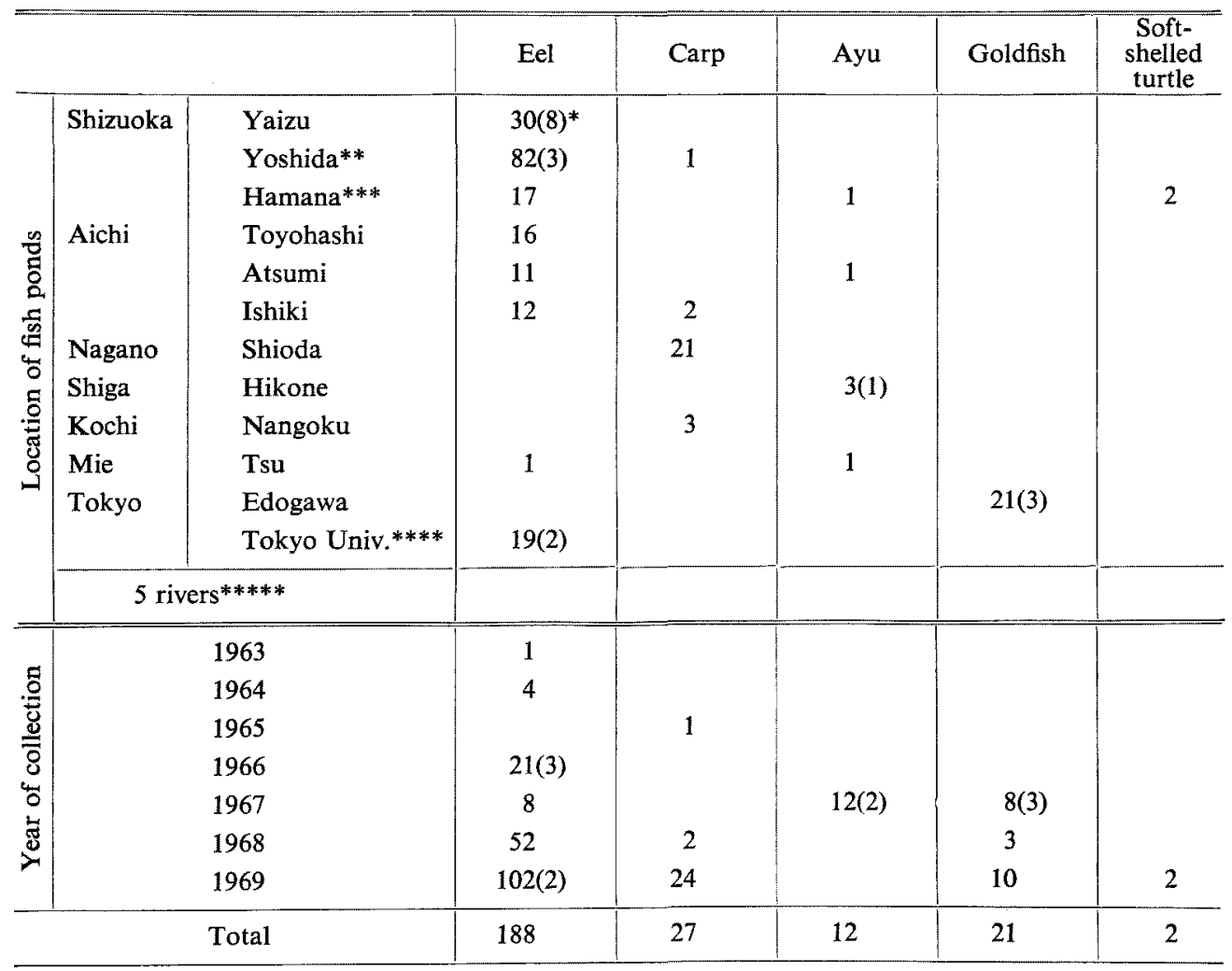

* Figures in parentheses indicate the number of strains which were lost before sensitivity tests with aminobenzyl penicillin, fradiomycin and kanamycin.

** Including Oigawa.

*** Including Shinohara, Maisaka, Bentenjima, Arai, and Kosai.

**** Experimental tanks in the campus of Tokyo Univ. into which eels were transferred several times from farm-ponds at Yoshida or Yaizu.

***** Naka R. (Ibaragi Pref.), Kuma R. (Kumamoto Pref.), Chikugo R. (Fukuoka Pref.), Toyo (Aichi Pref.). 
kanamycin sulfate (Sankyo), fradiomycin sulfate (Meiji), aminobenzyl penicillin (Meiji), furazolidone (Takeda), nifuriprinol (Dainippon), and sulfamonomethoxine (Daiichi).

Of these 9 drugs, fradiomycin, kanamycin and aminobenzyl penicillin were tested on 232 of the 250 strains, because 18 strains had been lost before performance of tests with these drugs. Chlortetracycline hydrochloride (Lederle), nitrofurazone (Dainippon), and sulfisoxazole (Yamanouchi) were used for additional sensitivity tests using 110 strains obtained before 1968.

3) Procedures used for sensitivity test: The serial dilution method in agar proposed by the Japan Society of Chemotherapy ${ }^{6}$ was employed, except for incubation temperature which was $28^{\circ} \mathrm{C}$ in the present study. Heart-infusion agar (Eiken) was used as a medium for sensitivity tests with antibiotics and nitrofuran derivatives. N,N-dimethylformamide was used as a solvent of nitrofuran derivatives. Ten milligrams of the drug was first dissolved in $5 \mathrm{ml}$ of the solvent and then the solution was diluted with the same amount of distilled water to make a stock solution. Twenty-four-hour-old cultures at $28^{\circ} \mathrm{C}$ in Tryptosoy broth (Eiken) were used as inocula. While in sensitivity tests with sulfa drugs use was made of KNIGHT's semisynthetic medium to which was added agar to give $1.5 \%$ concentration and all inocula were grown at $28^{\circ} \mathrm{C}$ for 24 hours in the same medium without agar. Each organism was tested at least twice for sulfa drugs. Controls were always run using A. liquefaciens $\mathrm{Y}-62$.

The highest dilution, or the minimum concentration, of a drug inhibitory to a test strain was taken as the MIC of the drug to the strain.

\section{Results}

The results of the sensitivity tests performed are shown in Table 2 and those of the additional tests in Table 3. From these tables and Table 4 which gives a comparison of inhibitory potencies of drugs, it may be said that most strains are highly sensitive to tetracycline, chloramphenicol, and chlortetracycline, moderately sensitive to the remaining drugs, except aminobenzyl penicillin to which they are highly resistant.

The distribution curves of sensitivities of the strains to the nine drugs are given in Fig. 1. As a curve at the top on the left of the figure shows, the 250 strains studied showed a sensitivity distribution curve bearing two peaks on the sensitive and resistant sides against tetracycline. This suggests that the strains, except three moderately sensitive strains showing MIC values between 3.1 and $12.5 \mathrm{mcg} / \mathrm{ml}$, may fall into two groups depending on their sensitivities to the drug; a large group consisting of highly sensitive strains showing MIC values from 0.2 to $1.6 \mathrm{mcg} / \mathrm{ml}$ and a small group of resistant strains situated within a MIC range from 25 to $250 \mathrm{mcg} / \mathrm{ml}$.

The sensitivity distribution curves against chloramphenicol and streptomycin have 
Table 2. Drug sensitivities of 250 strains of Aeromonas liquefaciens isolated from fishes (I).

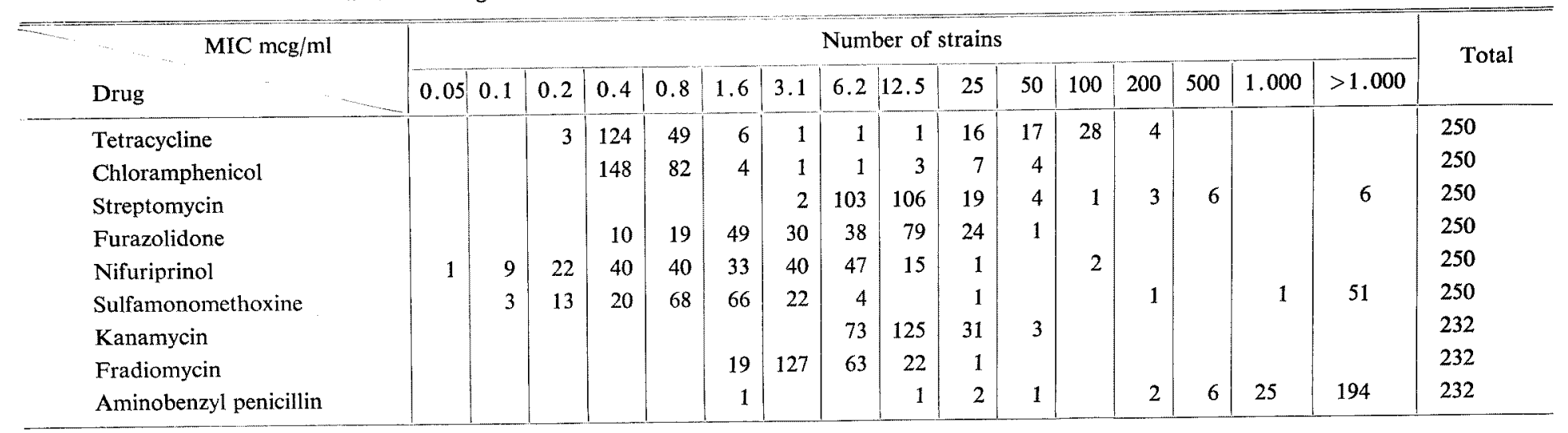

Table 3. Drug sensitivities of 110 strains of Aeromonas liquefaciens isolated from fishes (II. Results of additonal sensitivity tests).

\begin{tabular}{|c|c|c|c|c|c|c|c|c|c|c|c|c|c|c|c|}
\hline \multirow[b]{2}{*}{ Drug } & \multicolumn{14}{|c|}{ Number of strains } & \multirow{2}{*}{ Total } \\
\hline & 0.2 & 0.4 & 0.8 & 1.6 & 3.1 & 6.2 & 12.5 & 25 & 50 & 100 & 200 & 500 & 1.000 & $>1.000$ & \\
\hline $\begin{array}{l}\text { Chlortetracyline } \\
\text { Nitrofurazone } \\
\text { Sulfisoxazole }\end{array}$ & 9 & 57 & $\begin{array}{l}13 \\
15\end{array}$ & $\begin{array}{r}1 \\
3 \\
11\end{array}$ & $\begin{array}{r}1 \\
16 \\
38\end{array}$ & $\begin{array}{r}8 \\
26 \\
16\end{array}$ & $\begin{array}{r}10 \\
35 \\
6\end{array}$ & $\begin{array}{l}10 \\
29\end{array}$ & 1 & 1 & & & & 18 & $\begin{array}{l}110 \\
110 \\
110\end{array}$ \\
\hline
\end{tabular}




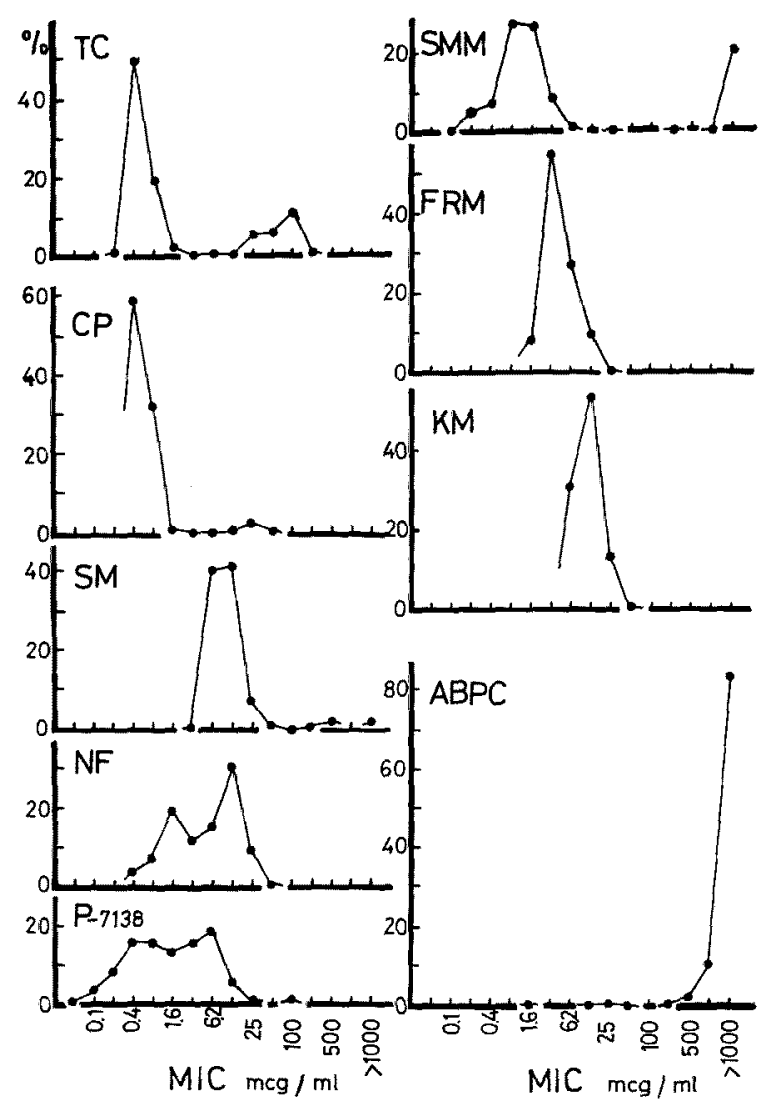

Fig. 1. Sensitivity distribution curves of Aeromonas liquefaciens strains against nine drugs.

Ordinate; percentage frequency

Abscissa; MIC levels

Abbreviations: TC; tetracycline, CP; chloramphenicol, $\mathrm{SM}$; streptomycin, NF; furazolidone, P-7138; nifuriprinol, SMM; sulfamonomethoxine, FRM; fradiomycin, KM; kanamycin, ABPC; aminobenzyl penicillin.

two and three peaks, respectively, though the peaks on the resistant side are all very small, suggesting the existence of a small number of strains resistant to these drugs. A curve at the top on the right of Fig. 1 clearly shows that there are a number of strains highly resistant to sulfamonomethoxine, though the majority of the strains are highly sensitive to the drugs.

On the contrary the strains showed a distribution curve of sensitivity having one peak against kanamycin and fradiomycin. The ranges of MIC of these drugs were narrow and there was no strain being far beyond the ranges and consequently it may be said that no strains were found resistant to these drugs.

The sensitivity distribution curves against two sorts of nitrofuran derivatives, so 
Table 4. Comparison of the inhibitory potencies of 12 drugs tested against Aeromonas liquefaciens.

\begin{tabular}{l|c|c}
\hline \multirow{2}{*}{} & \multicolumn{2}{|c}{ Minimum concentrations of drugs inhibitory to (mcg/ml) } \\
\cline { 2 - 3 } & $50 \%$ of the tested strains & $70 \%$ of the tested strains \\
\hline $\begin{array}{l}\text { Chloramphenicol } \\
\text { Tetracycline } \\
\text { Chlortetracycline }\end{array}$ & 0.4 & 0.8 \\
\hline $\begin{array}{l}\text { Sulfamonomethoxine } \\
\text { Sulfisoxazole } \\
\text { Nifuriprinol }\end{array}$ & 1.6 & 3.1 \\
\hline Fradiomycin & 3.1 & 6.2 \\
\hline Furazolidone & 6.2 & 12.5 \\
\hline $\begin{array}{l}\text { Streptomycin } \\
\text { Kanamycin } \\
\text { Nitrofurazone }\end{array}$ & 12.5 & 12.5 \\
\hline Aminibenzyl penicillin & $>1.000$ & $>1.000$ \\
\hline
\end{tabular}

far as the appearances go, had two peaks respectively, but it seems unreasonable to divide the strains into two groups, sensitive and resistant, either to furazolidone or to nifuriprinol, though there were 2 strains which were apparently resistant to nifuriprinol (Fig. 1, Table 2). The organism was highly resistant to aminobenzyl penicillin, but it is interesting to note that there were some strains which were sensitive to this drug.

There was found a correlation between the sensitivity of the organism to chemically

Table 5. Relation between the sensitivities of 110 strains of Aermonas liquefaciens to tetracycline and chlortetracycline.

\begin{tabular}{|c|c|c|c|c|c|c|c|c|c|c|}
\hline \multirow{2}{*}{\multicolumn{2}{|c|}{$\begin{array}{r}\mathrm{MIC} \\
\mathrm{mcg} / \mathrm{ml}\end{array}$}} & \multicolumn{9}{|c|}{ Chlortetracycline } \\
\hline & & 0.2 & 0.4 & 0.8 & 1.6 & 3.1 & 6.2 & 12.5 & 25 & 50 \\
\hline \multirow{11}{*}{ Tetracycline } & 0.2 & & & & & \multirow{11}{*}{1} & & & & \\
\hline & 0.4 & $7^{*}$ & 30 & 2 & & & & & & \\
\hline & 0.8 & 2 & 27 & 8 & & & & & & \\
\hline & 1.6 & & & 2 & 1 & & & & & \\
\hline & 3.1 & & & 1 & & & & & & \\
\hline & 6.2 & & & & & & & & & \\
\hline & 12.5 & & & & & & & 1 & & \\
\hline & 25 & & & & & & 7 & 4 & & \\
\hline & 50 & & & & & & 1 & 2 & 3 & \\
\hline & 100 & & & & & & & 3 & 4 & 1 \\
\hline & 200 & & & & & & & & 3 & \\
\hline
\end{tabular}

* Number of strains. 
Table 6. Relation between the sensitivities of 110 strains of Aeromonas liquefaciens to sulfanilamide derivatives.

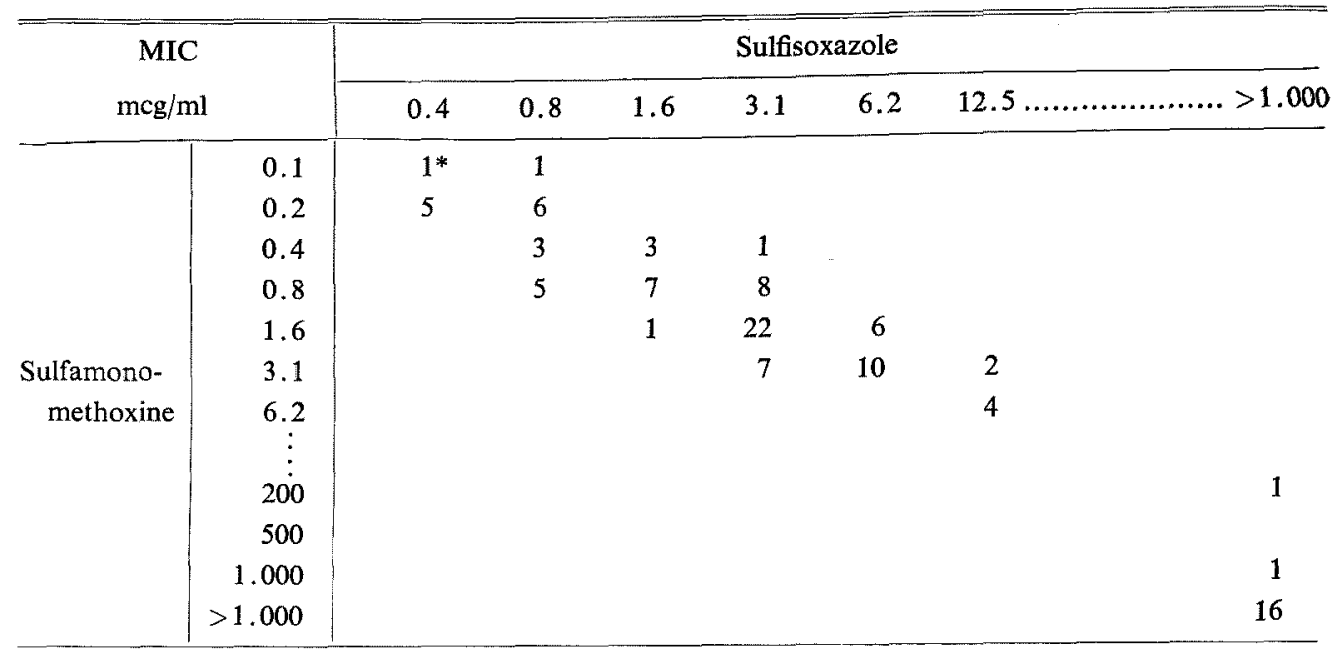

* Number of strains.

related drugs; that is, between tetracycline and chlortetracycline (Table 5), sulfamonomethoxine and sulfisoxazole (Table 6), and furazolidone, nitrofurazone and nifuriprinol (Table 7).

\section{Discussion}

There are several reports on the drug sensitivities of fish-pathogenic $A$. liquefaciens (synonymous to $A$. punctata; A. hydrophila, Pseudomonas punctata) ${ }^{7-16)}$. The sensitivities of the organism to various drugs reported by various authors are practically equal to those of our strains which are sensitive to respective drugs, though the numbers of strains they used were very limited and their methods of sensitivity test were different from one another and from ours.

In the foregoing chapter the present authors used the term 'resistant', but it is not necessarily easy to rigidly define 'resistant' strains. For example, on the basis of sensitivity distribution of the strains shown in Fig. 1, a group of strains showing MIC levels over $25 \mathrm{mcg} / \mathrm{ml}$ of tetracycline can be reasonably defined as resistant to tetracycline, but the question whether or not the 3 intermediately sensitive strains are also resistant has puzzled us. The same may be said of cases with chloramphenicol, streptomycin and sulfamonomethoxine. So it is inevitable to determine somewhat arbitrarily critical MIC levels for defining resistant $A$. liquefaciens.

In the present study critical MIC levels for defining resistant $A$. liquefaciens are tentatively determined as shown in Table 8 , by being chiefly based on the results of the present study and, in addition, by taking account of the standard MIC levels proposed 
Table 7. Relation among the sensitivities of 110 strains of Aeromonas liquefaciens to furazolidone, nitrofurazone and nifuriprinol.

\begin{tabular}{|c|c|c|c|c|c|c|c|c|c|c|c|c|c|c|c|c|c|c|}
\hline \multirow[t]{2}{*}{$\mathrm{MIC}$} & \multirow[b]{2}{*}{$\mathrm{mcg} / \mathrm{ml}$} & \multicolumn{9}{|c|}{ Nifuriprinol } & \multicolumn{8}{|c|}{ Nitrofurazone } \\
\hline & & 0.1 & 0.2 & 0.4 & 0.8 & 1.6 & 3.1 & 6.2 & 12.5 & 25 & 0.8 & 1.6 & 3.1 & 6.2 & 12.5 & 25 & 50 & 100 \\
\hline \multirow{8}{*}{ Furazolidone } & 0.4 & & $3^{*}$ & & & & & & & & & 1 & 2 & & & & & \\
\hline & 0.8 & 2 & 2 & 1 & 1 & & & & & & & 1 & 5 & & & & & \\
\hline & 1.6 & & 4 & 14 & 5 & & & & & & & 1 & 7 & 11 & 4 & & & \\
\hline & 3.1 & & 1 & 5 & 9 & 2 & 1 & & & & & & 2 & 11 & 5 & & & \\
\hline & 6.2 & & & 3 & & 7 & 5 & & & & & & & 2 & 12 & 1 & & \\
\hline & 12.5 & & & & 1 & 9 & 11 & 8 & 6 & 1 & & & & 2 & 12 & 22 & & \\
\hline & 25 & & & & & & 1 & 4 & 3 & & & & & & 2 & 6 & & \\
\hline & 50 & & & & 1 & & & & & & & & & & & & & 1 \\
\hline
\end{tabular}

* Number of strains.

Table 8. The MIC levels for defining drug-resistant Aeromonas liquefaciens and the number of resistant strains.

\begin{tabular}{|c|c|c|c|c|}
\hline & \multirow{2}{*}{$\begin{array}{c}\text { Criteria of drug resistance } \\
\text { (MIC levels defining drug- } \\
\text { resistant } A \text {. liquefaciens) } \\
(\mathrm{mcg} / \mathrm{ml})\end{array}$} & \multirow{2}{*}{$\frac{\text { No. of resistant strains }}{\text { No. of studied strains }}$} & \multicolumn{2}{|c|}{ Criteria for drug resistance $(\mathrm{mcg} / \mathrm{ml})$} \\
\hline & & & Shigella ${ }^{18}$ & $\begin{array}{c}\text { Gram-negative } \\
\text { bacteria }^{19 !}\end{array}$ \\
\hline Chloramphenicol & 25 & $11 / 250$ & 25 & $25-50$ \\
\hline Tetracycline & 25 & $65 / 250$ & 25 & $12.5-100$ \\
\hline Streptomycin & 100 & $16 / 250$ & 12.5 & $25-50$ \\
\hline Furazolidone & 50 & $1 / 250$ & 12.5 & $\longrightarrow$ \\
\hline Nifurprinol & 50 & $2 / 250$ & - & - \\
\hline Sulfamonomethoxine & 100 & $53 / 250$ & 50 & $200-800$ \\
\hline Fradiomycin & 100 & $0 / 232$ & 12.5 & - \\
\hline Kanamycin & 100 & $0 / 232$ & 12.5 & $12.5-50$ \\
\hline Aminobenzyl penicillin & 100 & $227 / 232$ & 25 & $50-400$ \\
\hline
\end{tabular}


by the Research Committee of the Shigella Strains in Japan for defining resistant Shigella ${ }^{18)}$, and those by the Research Committee of Gram-negative Bacterial Infections to define various resistant gram-negative bacteria ${ }^{19)}$. The number of drug-resistant strains of A. liquefaciens thus defined are given in the second column from the left of Table 8.

As shown in Table 8, out of the 232 strains studied $227(97.8 \%$ ) were highly resistant to aminobenzyl penicillin, and so it seemed appropriate to exclude aminobenzyl penicillin resistance from the discussion here of resistance patterns of A. liquefaciens strains.

Patterns of drug resistance of drug-resistant strains of $A$. liquefaciens are given in Table 9, which shows that 38 strains were two-drug-resistant, four strains three-drugresistant, and 8 strains four-drug-resistant.

Table 9. Drug-resistance patterns of drug-resistant strains of Aeromonas liquefaciens isolated from fishes.

\begin{tabular}{l|l|l|r}
\hline & \multicolumn{1}{|c|}{$\begin{array}{c}\text { No. of } \\
\text { strains }\end{array}$} & Resistance pattern* & $\begin{array}{c}\text { No of } \\
\text { strains }\end{array}$ \\
\hline & & CP & 3 \\
One-drug-resistant & & TC & 16 \\
& 28 & SM & 2 \\
& & NF (p-7138) & 2 \\
& & SA & 5 \\
\hline Two-drug-resistant & & TC, SA & 36 \\
& & TC, SM & 1 \\
\hline Three-drug-resistant & 38 & SM, NF (Furazolidone) & 1 \\
\hline Four-drug-resistant & & TC, SM, SA & 4 \\
\hline
\end{tabular}

* Abbreviations. TC: tetracycline, CP: chloramphenicol, SM: streptomycin, NF: nitrofurazone derivatives, $\mathrm{SA}$ : sulfanilamide derivatives.

It is well worth of notice that 36 of the 38 two-drug-resistant strains had TC, SAresistance (tetracycline-sulfanilamide resistance) and the 4 three-drug-resistant strains and the 8 four-drug-resistant strains were all resistant to TC and SA. Accordingly it may be said that TC, SA-resistance is a characteristic resistance pattern of durg-resistant A. liquefaciens.

It is interseting to note that no drug-resistant strain was found among 6 strains isolated from wild diseased ayu. The MIC values of drugs to those strains were as follows: tetracycline, chlortetracycline, chloramphenicol, and nifurprinol, $<0.8 \mathrm{mcg} / \mathrm{ml}$; fradiomycin and furazolidone, $<3.1 \mathrm{mcg} / \mathrm{ml}$; sulfamonomethoxine, $<6.2 \mathrm{mcg} / \mathrm{ml}$; streptomycin, nitrofurazone, and sulfisoxazole, $<12.5 \mathrm{mcg} / \mathrm{ml}$; kanamycin, $<25 \mathrm{mcg} / \mathrm{ml}$; aminobenzyl penicillin, $1000 \mathrm{mcg} / \mathrm{ml}$. It seems, however, to be too early to discuss whether or not this is due to the fact that wild ayu have no chance of coming into contact with chemotherapeutics. 


\section{References}

1) Anderson, E. S.: Ann. Rev. Microbiol., 22, 131-180 (1968).

2) SNIESzko, S. F. and G. L. Bullock: Prog. Fish-Cult., 19, 99-107 (1957).

3) SNIEszko, S. F. and G. L. Bullock: U.S.D.I., Fish and Wildl. Serv., Fish Bull., 125, 555-564 (1957).

4) G. L. Bullock: Develop. Appl. Microbiol, 5, 101-108 (1964).

5) R. W. H. Schubert: Int. J. Systematic Bacteriol., 17, 23-37 (1967).

6) JaPAN Society of Chemotheraphy Sub Commttiee on Mic: Chemotherapy, 16, 1, 98-99 (1968).

7) W. SCHÄPERCLAUS: Z. Fischerei, 5, 1-60 (1956).

8) W. SCHÄPERClAUS: ibid., 7, 509-628 (1958).

9) T. Hoshina: J. Tokyo Univ. Fish., 6, 1-105 (1962).

10) E. KaraseK: Z Zbl. Vet. Med., 14, 663-670 (1967).

11) M. ShImizu and Y. TAKaSE: This Bull., 33, 544-554 (1967).

12) M. Shtmizu and Y. TAKaSe: Fish Path., 2, 59-67 (1967).

13) K. Muroga and S. Egusa: ibid., 2, 141-147 (1968).

14) G. L. Bullock and D. Collis: Bureau of Sport Fisheries and Wildlife Technical Paper, 32, 9 pp. (1969).

15) J. A. RoBinson et al.: ibid., 35, 7 pp. (1969).

16) R. KusUdA and Y. TAKaHASHI: Fish Path., 4, 87-97 (1970).

17) K. Shiraki et al.: ibid., 4, 130-137 (1970).

18) T. EZAKI et al.: Chemotherapy, 17, 447-451 (1969).

19) S. IshiYama et al.: ibid., 17, 42-46 (1969). 